2018-04

Family-centered bereavement practices

in Danish intensive care units: a

cross-sectional national survey

\title{
Egerod, I
}

http://hdl.handle.net/10026.1/13039

10.1016/j.iccn.2017.10.003

Intensive and Critical Care Nursing

Elsevier

All content in PEARL is protected by copyright law. Author manuscripts are made available in accordance with publisher policies. Please cite only the published version using the details provided on the item record or document. In the absence of an open licence (e.g. Creative Commons), permissions for further reuse of content should be sought from the publisher or author. 
Egerod I, Kaldan G, Coombs M \& Mitchell M 2018. Family-centered bereavement practices in Danish intensive care units: a cross-sectional national survey. Intensive and Critical Care Nursing 45, 52-57 https://doi.org/10.1016/j.iccn.2017.10.003

Author copy. Accepted $19^{\text {th }}$ October 2017

\section{ABSTRACT}

Background: Mortality in Danish intensive care units (ICU) continues at 30\%, resulting in a large number of bereaved family members being cared for in the ICU.

Objectives: To investigate the provision of bereavement care and follow-up services for bereaved families in Danish ICUs.

Methodology: Self-administered computerized cross-sectional nation-wide survey of Danish ICU nurses.

Results: Nurses at 46 of 48 (96\%) ICUs in Denmark responded. Bereavement care at the time of patient death included viewing the patient in ICU (100\%), and in the hospital mortuary (59\%). Information about hospital-based follow-up for the family was provided in $72 \%$ of units, whereas only one unit provided information on community-based bereavement follow-up. Bereavement follow-up services after hospitalization were offered to families in 59\% of ICUs and included an ICU visit, meeting with the staff present at the time of death, a letter of condolence, a phone call to the family, referral to a priest or clergyman, or referral to counseling. Although many interventions were common, there were variations within the elements offered. Nurses and physicians were the most consistent health care staff involved in bereavement services.

Conclusion: Most ICUs in Denmark offered bereavement follow-up services, but these varied in their approach, were not evidence-based, and lacked formal evaluation. More systematic quality improvement of bereavement practices is required. 
Key words: Bereavement, ICU, nursing, family-centered care, follow-up services

\section{INTRODUCTION}

The aim of any Intensive Care Unit (ICU) is the monitoring and support of patients with a lifethreatening illness enabling diagnostic measures to be performed, appropriate interventions to be administered, and thereby improve patient outcome (Valentin and Ferdinande 2011). This is reflected in general recommendations for Danish ICUs where intensive therapy is provided for patients with potentially reversible conditions (Ilkjær et al. 2013). Nevertheless mortality within 30 days of ICU admission in Denmark remains high at 27\% (Christensen and Faber 2014). This suggests that a large number of family caregivers are faced with the death of their relative in the ICU (Fridh et al. 2009; van der Klink et al. 2010). Some ICU patient deaths are unexpected and others are anticipated as the patient transitions from intervention to end-of-life care and controlled death (Coombs et al. 2012).

Resultant from these different trajectories of death, bereaved family members can experience different types of grief, such as uncomplicated or complicated grief, that can impact upon their mental and physical health outcomes (Aoun et al. 2015). Whereas uncomplicated grief is a normal, self-limiting reaction to bereavement, complicated grief is where intense, persistent grief lasts for more than six months after the loss, impairing normal psychological, social, and daily functioning (Nielsen et al. 2017a; Shear et al. 2011; Zisook and Shear 2009). Given such impact, it is important 
to prevent, identify and treat complicated grief reactions to prevent prolonged suffering and dysfunction in family caregivers.

Family-centered care for relatives of patients dying in the ICU is not a new concept (Campbell and Thill 2000), and has indeed informed health policy. The Danish Health Authority has provided a guide for care of the bereaved family after the death of a patient from critical illness (SST 2016), wherein it is recommended that the family receives systematic information after the death of the patient. Further it is recommended that the bereaved family receives a final consultation at the hospital with a follow-up phone call. Whilst the profile of family-centered care in policy is clear, evidence of the impact of family-centered bereavement interventions in practice remains variable. A randomized clinical trial in 2007 compared the customary end-of-life family conference in ICU with a proactive intervention preparing the family for the patient's death (Lautrette et al. 2007). It was concluded that a brochure on bereavement and proactive communication reduces the burden on families at this time. Ten years later, a study tested the effect of a condolence letter on family members' grief symptoms and found that the letter failed to alleviate grief symptoms, and had potential to increase symptoms of post-traumatic stress and depression (Kentish-Barnes et al. 2017).

The most effective way to offer bereavement support has still not been determined internationally. with a recent audit of ICUs in the United Kingdom concluded that bereavement care remains underdeveloped (Berry et al. 2017). An American survey showed that most ICUs did not provide bereavement follow-up services, but that hospitals with palliative care units were more likely to do so (McAdam and Erikson 2016). A survey of bereavement support in Australia and New Zealand reported that key components of family bereavement support have remained unchanged over the past decade, with little investment noted in this area (Mitchell et al. 2017). 
To date, bereavement support in Danish ICUs has not been explored. The aim of this study was to investigate the provision of bereavement care and follow-up services for the family of patients that died in Danish ICUs. We wished to gain an overview of interventions offered to the family of deceased patients in ICUs, to describe characteristics of bereavement support, and to identify the role of ICU staff participating in these services.

\section{METHODS}

We conducted a self-administered computerized cross-sectional nation-wide survey of Danish ICU nurses. The survey was a collaborative replication of the 2016 study of bereavement support in Australia and New Zealand (Coombs et al. 2016; Mitchell et al. 2017). By undertaking a replication study, we were able to accumulate evidence within this area of research and explore the comparability and generalizability of results. In this study "bereavement care" refers to interventions provided for the family caregivers at the time of death of the patient in ICU, and "bereavement follow-up services" refers to family support at a later time.

\section{Sample population}

We compiled a list of the 48 ICUs in Denmark and contacted each unit to identify one or two nurses who were willing to respond to the survey. We specifically targeted nurse managers in the ICUs, but also approached other nurses with particular knowledge of bereavement services in that unit to improve the response rate and widen the scope of information. At each ICU we chose a primary respondent, preferably the nurse manager on site, to ensure equal representation at all participating units. If there was a secondary respondent, we only included free-text responses from that respondent. Invitations with a link to the survey were sent to the work emails of the potential respondents at each unit. Two reminders were sent to all respondents at three and four weeks. 


\section{Data collection tool}

The survey tool developed by Mitchell et al. (2017) was used and consisted of 30 items within four sections: I. Personal and unit demographics, II. Model of bereavement services, III. Workforce model, and IV. Service evaluation. The survey was translated from English to Danish (translation and back-translation by bi-lingual authors) and piloted by asking five experienced nurses at different ICUs to complete and comment on the survey. A few changes were made to the Danish version, for example, the title Clinical Nurse Consultant and the Post Graduate Certificate Diploma do not exist in Denmark and were omitted. Critical care nursing certification in Denmark is a nonacademic program, which was added. The original survey in Australia and New Zealand was powered by SurveyMonkey®, but we chose SurveyXact in this study, as it is the leading web-based survey system in Scandinavia. The system is free of charge and easy to use, providing a report of results and a database that exports easily to Excel and SPSS.

\section{Data analysis}

Descriptive statistics were used to analyze the closed-ended items in the survey. Categorical variables were summarized as frequencies shown as numbers and percentages. Although SurveyXact provided a report of the results, we transferred data to IBM SPSS version 22 for calculations. The free text comments from all respondents were comprehensively summarized for each item as the sample.

\section{Ethical considerations}

After consulting the Danish Data Protection Agency further approval was not required. Potential respondents were provided with information on the surveyin the initial contact email. . In this 
information, it was started that consent was assumed by completion of the survey and that confidentiality would be assured as only aggregate data was to be reported.

\section{RESULTS}

The results are presented in the order of the four sections in the survey. The free-text results are presented with each item. We compared the responses of primary and secondary respondents and found no significant differences other than their job titles. Free-text responses from secondary respondents added to the information on how bereavement follow-up services are provided.

\section{Personal and unit demographics}

Respondents and setting

We received responses from 58 nurses at 46 ICUs situated in 29 hospitals. This sample represents 96\% (46/48) of Danish ICUs. All respondents were highly experienced clinicians and educationally well prepared. Demographic characteristics of primary respondents $(n=46)$ are shown in table 1. Secondary respondents $(\mathrm{n}=12)$ are not included in the demographic characteristic calculations. All ICUs were in public hospitals, most were at Level II and III mixed medical/surgical units treating both adult and pediatric patients, see table 1 .

[Table 1 Demographic characteristics]

\section{Model of bereavement services}

Bereavement care

Bereavement care was offered to the family at the time of the patient's death in ICU. All 46 units (100\%) offered viewing of the deceased in ICU, but only 27 units (59\%) assisted the family to view 
the patient in the hospital mortuary. Information regarding hospital-based follow-up for the family was provided at 33 units (72\%), whereas only one unit provided information on community-based bereavement follow-up.

\section{Bereavement follow-up services}

Bereavement follow-up services were offered to the family at 27 (59\%) of the 46 ICUs. The elements of services are shown in table 2. Although many interventions were common, there were variations within the elements, suggesting a lack of national consensus. According to free-text responses bereavement follow-up had been offered for less than ten years at 11 units and 11-20 years at ten units. One respondent wrote: “We don't have set rules, but we usually call the family 23 weeks after the patient died. If they need to talk, we arrange a date".

[Table 2 Elements of bereavement follow-up services]

A letter of condolence was offered at $13(28 \%)$ units and one neurointensive unit offered a letter of appreciation to family of organ donors. The timing and content of the letters varied. According to the free-text responses most letters were sent to the family by nurses or a secretary after 2-5 weeks. Some letters extended an invitation to meet with the nurse or physician attending to the patient at the time of death: "We offer the closest family a follow-up visit with the nurse who was present when the patient died, or the primary nurse, about 6-8 weeks after the patient's death".

A phone call to the family was offered at $12(26 \%)$ units. According to the free-text responses the call was made at 1-8 weeks after the patient's death. In most units it was the nurse who was present at the time of death who made the call. The purpose of the call was to ask if the family had any unanswered questions or to invite the family to come to the hospital to talk with a nurse and, 
perhaps, a physician. The respondents reported that a call to the family was particularly important after the death of a child. "We offer the family a phone call. If they agree, we call them after 3-4 weeks and offer a visit. An ICU nurse from the follow-up group makes the call and talks to the family if they visit".

A return visit to ICU was offered at 19 (41\%) units. According to the free-text responses the ICU visit was often arranged so the family could talk to a nurse or physician, preferably the individuals who had been present at the patient's death. During the meeting the nurse would review the patient's illness trajectory and explain some of the equipment used in ICU. "The family is invited to come and talk to the nurses. The visit lasts about an hour including a visit to ICU, if they wish".

Referrals to counseling were provided at some ICUs, for example, chaplain at 11 (24\%) units, psychologist at $2(4 \%)$ units, or other. According to the free-text responses referrals included physician, intensivist, anesthesiologist, primary physician, or healthcare nurse. “As mentioned earlier we don't have a standard solution, but we look at the needs of the individual family. If they need follow-up with a chaplain we arrange it, but most often they wish to speak to the attending physician and perhaps a nurse". Some units referred families to support groups with people with similar circumstances.

\section{Workforce model}

The number and type of health professionals involved in bereavement follow-up varied. Services involved one to more than six staff members, see table 3 . The professional groups that were responsible for bereavement follow-up included: ICU nurse managers, intensivists, ICU nurses, secretaries, and other providers, for example, primary nurse, physician or organ donor coordinator (see table 3). Organization of bereavement follow-up varied between permanent and rotating staff 
members including nurses, physicians and nurse managers, depending on whom was present at the time of death. Routine debriefing of staff was offered at $24(52 \%)$ units. According to the free text responses, debriefing after a particularly traumatic death was customary at most units, but only few units had permanent members in the follow-up team. "It is the staff that was present when the patient died that talk to the family, if at all possible".

[Table 3 The workforce model]

\section{Service evaluation}

Bereavement follow-up had been evaluated at 9 (20\%) units using different assessment methods. Evaluation included verbal feedback from family or staff, family survey or staff interviews performed either annually, monthly or continuously. Results of the evaluation had brought some changes, such as updating the ICU web homepage, revising local ICU guidelines on bereavement care, or improving the method of contacting the family after the patient's death. Most units invited the family to meet with nurses and physicians together, but one unit preferred to keep family meetings with nurses or physicians separate.

The parts of the bereavement services that were perceived as most appreciated by the family were meeting with the nurse and physician, a phone call to answer any questions, a review of their relative's illness trajectory, and understanding that their relative's death was unavoidable. Half of the respondents had some opinion of how their services were received by the family, for example they considered that bereavement services provided closure, families were appreciative, services were meaningful, and the nurses were perceived as empathetic. "They experience a good conclusion to their trajectory. They had expected a difficult kind of dialogue with family members, but actually they experience gratitude. It's not as difficult as expected". 
According to the free text comments, some units considered improving bereavement followup by being more consistent, offering dialogue with the family and the ICU staff, group consultations, nurse-led consultations, sending postcards, providing aftercare meetings to include family members, focusing on parents of children with deformities, focusing on families of organ donors, and offering families to take their relative home to die. Our survey confirmed the heterogeneous nature of the services and illustrated variability in service provision among the units surveyed.

\section{DISCUSSION}

In our study we aimed to investigate the provision of bereavement care and follow-up services for the family of patients that died in Danish ICUs. Our main finding confirmed the variability of services and highlighted the good-will of individual staff members providing family meetings to support the bereaved. This activity might also have indirectly helped nurses to cope with the frequent deaths in ICU, but we have not explored this in the present study.

A model of bereavement follow-up services in Denmark has not been described beyond the general recommendations of the Danish Health Authority (SST 2016). Most ICUs have some guidelines at the local level, but the survey demonstrates some uncertainty regarding the content and implementation of these guidelines. Results from this study suggest that bereavement practices, to some extent, rely on individual providers. There are other ICU initiatives that demonstrate similar variability and local practices. The provision of ICU follow-up and ICU diaries in the Scandinavian countries has been described as a part of aftercare for post-ICU patients and their close family. It has been shown that these services emerged as bottom-up initiatives undertaken by nurses with a personal interest, rather than a top-down approach informed by national guidelines (Egerod et al. 
2011; Egerod et al. 2013). In this light, variability in bereavement services in Denmark is not remarkable.

In our study, bereavement care included viewing the patient after death, and informing the family of follow-up services. Family presence during the dying process is important and helps those present acknowledge the transition from life to death (Hadders, 2008). Results of our study support views expressed in Hadders' (2008) essay on the standardization of hospital death in Norway, where nurses encourage relatives to be at the bedside when a family member is dying, and to view the family member after death. . Hadders (2008) also advocated that nurses invite relatives to wash the patient or assist during postmortem care; this element of bereavement care was not identified in the narrative responses of our survey, so further comment cannot be offered..

There are several barriers to the provision of bereavement services in ICU. The first is that ICU bereavement follow-up has not historically been an integral part of the treatment regime, and for this reason has not been funded except when part of a research project (Jensen et al. 2015). A second barrier might be that family-centered care formally falls outside of the domain of patient treatment and care, particularly when staff are busy or resources constrained. These issues may help explain why the provision of family bereavement follow-up has been sporadic in Danish ICUs with bereavement care $=$ often driven by the good-will of individual practitioners, rather than a part of the concerted effort to provide family-centered intensive care. From this, it is clear that organizational barriers to implementation of bereavement follow-up need to be investigated further (McAdam and Erikson 2016).

The bereavement workforce model results demonstrated variability in the number and type of staff involved in bereavement follow-up. Although bereavement practices at most units included nurses, many units also included physicians or other professionals. In most units, individuals who 
had been present during the patient's death provided bereavement care and follow-up and in all sites, this contact occurred in months after the patient's death. This demonstrates some variance to practices identified in Australasia where recognized ICU bereavement teams are the norm (Mitchell et al. 2017).

Bereavement interventions are focused on preventing the detrimental effects of long-term unresolved grief (Fauri et al. 2000). Sudden and unexpected death, an event experienced in ICU,is known to have profound consequences for the family unit(Harrop et al. 2016). However, most studies of bereavement support fail to distinguish between types of grief. As one of the desired outcomes of follow-up services is to assist in the prevention of complicated grief (Nielsen et al. 2017b) with signs of prolonged grief, by definition, occuring six months after bereavement. It is difficult therefore to determine how the bereavement interventions, as described in this study, would have an effect on complicated grief. There is need for a clearer articulation of what the purpose of bereavement follow-up is, whether increased understanding of events in ICU, or reduction in complex grief reactions. If it is the latter, then a more informed assessment after six months is required to determine which families require support.

Few units in our study had evaluated their bereavement follow-up services, and those that had used a variety of methods, with little evidence of systematic approaches being used. This could be improved in the future by undertaking studies to describe the types of grief experienced by the family of patients who die in ICU and determine who might benefit from bereavement support, and what elements of support are important (Aoun et al. 2015). 
When comparing our results to those of the original study (Mitchell et al 2017), the study in Australia and New Zealand surveyed a larger number of ICUs than in Denmark, but the response rate was lower (Mitchell et al. 2017). This may be due to the smaller geographical size of Denmark making direct correspondence with a key person in each ICU more manageable. However, it appears that bereavement services in Australia and New Zealand were more formalized than in Denmark, and although there was variation in sending a sympathy card to families but most Australasian units undertook follow-up calls with families.. Interestingly, an important component of bereavement services across all three countries (Denmark, Australia and New Zealand) was the debriefing of ICU staff after a traumatic death and while some bereavement follow-up services were managed by social workers in Australia, the services in Denmark and New Zealand are mostly managed by nurses.

Although the informants in our study were very experienced nurses and the response rate was exceptionally high, our study was limited by recruitment processes. We invited two nurses at each ICU to participate in our survey to increase the number of respondents. Only 12 units provided two respondents, so we decided to use only the primary respondent replies in the statistical analysis to ensure equal distribution among the participating 46 units. Responses of the remaining respondents were included in reporting of the free-text data to increase the richness of the results. This has enabled us to provide a comprehensive description of bereavement practices at Danish ICUs.

\section{Conclusions}

It is clear that offering support to the family after the death of a relative in ICU is an important area of practice for ICU nurses.. However, results from this study demonstrate that whilst most units in Denmark offered bereavement follow-up services, these varied in approach, were not evidence- 
based, and evaluation of the services was lacking. From this we conclude that comprehensive bereavement care has not yet been fully integrated in Danish ICUs. In the future, we recommend systematic quality improvement of bereavement practices aimed at supporting the grief process of the patient's family.

\section{REFERENCES}

Aoun, S.M., Breen, L.J., Howting, D.A., Rumbold, B., McNamara, B., \& Hegney, D., 2015. Who needs bereavement support? A population based survey of bereavement risk and support need. PLoS.One., 10, (3) e0121101.

Berry, M., Brink, E., \& Metaxa, V., 2017. Time for change? A national audit on bereavement care in intensive care units. J Inten. Care Soc. 18, 11-16.

Campbell, M.L., Thill, M., 2000. Bereavement follow-up to families after death in the intensive care unit. Crit Care Med. 28, 1252-1253.

Christensen, S., Faber, T., 2014, Årsrapport 2013/2014, Dansk Intensiv Database [Annual Report Danish Intensive Database] Denmark.

Coombs, M., Mitchell, M., James, S., Wetzig, K., 2016. Intensive care bereavement practices across New Zealand and Australian intensive care units: a qualitative content analysis. J.Clin.Nurs.

Coombs, M.A., Addington-Hall, J., Long-Sutehall, T., 2012. Challenges in transition from intervention to end of life care in intensive care: a qualitative study. Int.J.Nurs.Stud. 49, 519527.

Egerod, I., Risom, S.S., Thomsen, T., Storli, S.L., Eskerud, R.S., Holme, A.N., Samuelson, K.A., 2013. ICU-recovery in Scandinavia: a comparative study of intensive care follow-up in Denmark, Norway and Sweden. Intensive Crit Care Nurs., 29, (2) 103-111.

Egerod, I., Storli, S.L., Akerman, E., 2011. Intensive care patient diaries in Scandinavia: a comparative study of emergence and evolution. Nurs.Inq. 18, 235-246.

Fauri, D.P., Ettner, B., Kovacs, P.J., 2000. Bereavement services in acute care settings. Death.Stud., 24, 51-64.

Fridh, I., Forsberg, A., Bergbom, I., 2009. Close relatives' experiences of caring and of the physical environment when a loved one dies in an ICU. Intensive Crit Care Nurs. 25, 111-119.

Hadders H., 2009. Medical practice, procedure manuals and the standardisation of hospital death. Nurs Inq. 16, 22-32.

Harrop, E., Morgan, F., Byrne, A., Nelson, A., 2016. "It still haunts me whether we did the right thing": a qualitative analysis of free text survey data on the bereavement experiences and support needs of family caregivers. BMC.Palliat.Care. 15, 92.

Ilkjær, S., Pawlowicz, M., Thormar, K., Bonde, J., Iversen, S., 2013, Generelle rekommendationer for intensiv terapi i Danmark [General recommendations for intensive therapy in Denmark] Denmark. 
Jensen, J.F., Thomsen, T., Overgaard, D., Bestle, M.H., Christensen, D., Egerod, I., 2015. Impact of follow-up consultations for ICU survivors on post-ICU syndrome: a systematic review and meta-analysis. Intensive Care Medicine. 41, 763-775.

Kentish-Barnes, N., Chevret, S., Champigneulle, B., Thirion, M., Souppart, V., Gilbert, M., et al., 2017. Effect of a condolence letter on grief symptoms among relatives of patients who died in the ICU: a randomized clinical trial. Intensive Care Med. 43, 473-484.

Lautrette, A., Darmon, M., Megarbane, B., Joly, L.M., Chevret, S., Adrie, C., et al., 2007. A communication strategy and brochure for relatives of patients dying in the ICU. N.Engl.J.Med. 356, 469-478.

McAdam, J.L. Erikson, A., 2016. Bereavement Services Offered in Adult Intensive Care Units in the United States. Am.J.Crit Care. 25, 110-117.

Mitchell, M., Coombs, M., Wetzig, K., 2017. The provision of family-centred intensive care bereavement support in Australia and New Zealand: Results of a cross sectional explorative descriptive survey. Aust.Crit Care. 30, 139-144.

Nielsen, M.K., Neergaard, M.A., Jensen, A.B., Vedsted, P., Bro, F., Guldin, M.B., 2017a. Predictors of Complicated Grief and Depression in Bereaved Caregivers: A Nationwide Prospective Cohort Study. J.Pain Symptom.Manage. 53, 540-550.

Nielsen, M.K., Neergaard, M.A., Jensen, A.B., Vedsted, P., Bro, F., Guldin, M.B., 2017b. Preloss grief in family caregivers during end-of-life cancer care: A nationwide population-based cohort study. Psychooncology.

Shear, M.K., Simon, N., Wall, M., Zisook, S., Neimeyer, R., Duan, N., et al., 2011. Complicated grief and related bereavement issues for DSM-5. Depress.Anxiety. 28, 103-117.

SST 2016. Mødet til pårørende til personer med alvorlig sygdom. Anbefalinger til sundhedspersonale [Meeting the needs of the family of people with critical illness. Recommendations for healthcare professionals]. Copenhagen: Danish Health Authority.

Valentin, A. Ferdinande, P., 2011. Recommendations on basic requirements for intensive care units: structural and organizational aspects. Intensive Care Med. 37, 1575-1587.

van der Klink, M.A., Heijboer, L., Hofhuis, J.G., Hovingh, A., Rommes, J.H., Westerman, M.J., Spronk, P.E., 2010. Survey into bereavement of family members of patients who died in the intensive care unit. Intensive Crit Care Nurs. 26, 215-225.

Zisook, S. Shear, K., 2009. Grief and bereavement: what psychiatrists need to know. World Psychiatry. 8, 67-74.

\section{Bullet points}

- Bereavement follow-up services in Danish intensive care units are variable

- General guidelines from the Danish Health Authority exist, but are not consistently followed

- We recommend systematic quality improvement of bereavement practices aimed at supporting the grief process of the patient's family 
Table 1 Demographic characteristics

Primary respondents $(n=46)$

\begin{tabular}{|c|c|c|c|}
\hline Roles of nurses & $\begin{array}{l}\text { ICU nurse manager } \\
28(61 \%)\end{array}$ & $\begin{array}{l}\text { Clinical nurse specialist } \\
3(7 \%)\end{array}$ & $\begin{array}{l}\text { Other } \\
13(28 \%)\end{array}$ \\
\hline Education of nurses & $\begin{array}{l}\text { ICU certification } \\
26(57 \%)\end{array}$ & $\begin{array}{l}\text { Master's degree } \\
14(31 \%)\end{array}$ & $\begin{array}{l}\text { PhD-degree } \\
2(4 \%)\end{array}$ \\
\hline $\begin{array}{l}\text { Experience of nurses } \\
\text {-General nursing } \\
\text {-ICU nursing }\end{array}$ & $\begin{array}{l}<10 \text { years } \\
1(2 \%) \\
5(11 \%)\end{array}$ & $\begin{array}{l}10-20 \text { years } \\
8(18 \%) \\
23(50 \%)\end{array}$ & $\begin{array}{l}21 \text { years+ } \\
33(72 \%) \\
14(30 \%)\end{array}$ \\
\hline \multicolumn{4}{|c|}{ Hospitals ( $n=29$ ) } \\
\hline Hospital type & $\begin{array}{l}\text { Private } \\
0\end{array}$ & $\begin{array}{l}\text { Public } \\
29(100 \%)\end{array}$ & \\
\hline ICU level & $\begin{array}{l}\text { Level I } \\
4(8 \%)\end{array}$ & $\begin{array}{l}\text { Level II } \\
21(46 \%)\end{array}$ & $\begin{array}{l}\text { Level III } \\
21(46 \%)\end{array}$ \\
\hline ICU type & $\begin{array}{l}\text { Med/surg. } \\
37(80 \%)\end{array}$ & $\begin{array}{l}\text { Neuro } \\
4(9 \%)\end{array}$ & $\begin{array}{l}\text { Thorax } \\
5(11 \%)\end{array}$ \\
\hline ICU patient mix & $\begin{array}{l}\text { Adult } \\
23(50 \%)\end{array}$ & $\begin{array}{l}\text { Adult/pediatric } \\
19(41 \%)\end{array}$ & $\begin{array}{l}\text { Pediatric } \\
0\end{array}$ \\
\hline
\end{tabular}

Level I: capable of providing immediate resuscitation and short term cardio-respiratory support

Level II: capable of providing a high standard of general intensive care, including complex multi-system life support Level III: capable of providing comprehensive critical care including complex multi-system life support for an indefinite period 
Table 2 Elements of bereavement follow-up services $(n=46)$

\begin{tabular}{ll}
\hline Bereavement follow-up service weeks or months after patient death & $\mathrm{n}(\%)$ \\
\hline ICU visit for family & $19(41 \%)$ \\
Meeting with medical staff by request & $14(30 \%)$ \\
Letter of condolence & $13(28 \%)$ \\
Phone call to family & $12(26 \%)$ \\
Referral to priest or clergyman & $11(24 \%)$ \\
Meeting with medical staff as routine & $11(24 \%)$ \\
Referral to other counseling & $5(11 \%)$ \\
Referral to psychologist & $2(4 \%)$ \\
Support group & -
\end{tabular}


Table 3 The workforce model

\begin{tabular}{lll}
\hline Items & Staff & $\begin{array}{l}\text { Number (\%) } \\
\text { of ICUs }\end{array}$ \\
& & $8(17 \%)$ \\
Number of staff members involved & 1 staff member & $6(13 \%)$ \\
& $2-3$ staff members & $1(2 \%)$ \\
& $4-6$ staff members & $7(15 \%)$ \\
Type of professionals involved & ICU nurse manager & $3(7 \%)$ \\
& Intensivist & $13(28 \%)$ \\
& ICU nurse & $9(20 \%)$ \\
& Secretary & $7(15 \%)$ \\
& Other & $6(13 \%)$ \\
Management of follow-up & & $9(20 \%)$ \\
& Permanent group of staff & $11(24 \%)$ \\
\hline
\end{tabular}

